\title{
Forzados a ser libres. Kant y la teoría republicana del derecho, Juan Ormeño Karzulovic y Miguel Vatter, (ed.)
}

Virgilio Ruiz Rodríguez

Forzados a ser libres

Kant y la teoria republicana del derecho

Juan Ormeha Karzulowic

Miguet Vatter (editores)

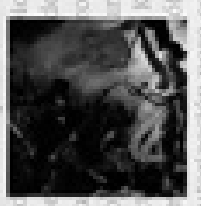

5.

Juan Ormeño Karzulovic y Miguel Vatter (editores). Forzados a ser libres. Kant y la teoría republicana del derecho. Santiago de Chile: Fondo de Cultura Económica, 2017, 243 páginas.
En la introducción de este libro se plantea la importancia que tiene hoy la Doctrina del derecho de Kant, como fundamento de la idea del Estado de derecho. Este juicio, aunque polémico, es prueba suficiente de la importancia de esta obra en la filosofía política contemporánea.

Kant no era considerado un político fundamental a la altura de $\mathrm{Ma}$ quiavelo, Hobbes, Hegel o Marx. Sin embrago, tras la publicación de la obra de J. Rawls, Una teoría de la justicia, el pensamiento político de Kant ha sobrepasado a los autores anteriores, debido a la vindicación rawlsiana del contractualismo; o a la formulación más política que Rawls dio a su teoría lo cual, argumentó, se debía al cons- 
tructivismo kantiano. Con ello, la filosofía del derecho se ha mantenido en un modesto segundo plano.

Los ensayos que conforman el libro tienen como objetivo justificar el renovado interés por la filosofía kantiana del derecho, cuyo texto principal sería la Introducción a la Doctrina del derecho. En ella, Kant parece revolucionar los postulados de gran parte de la tradición iusfilosófica occidental. Sentó una nueva doctrina del derecho para un mundo político sacudido por las revoluciones francesa y norteamericana. El propósito de esta antología es investigar el significado político y filosófico de dicha doctrina, y las nuevas bases sobre las cuales Kant pretendió establecer un concepto moderno de derecho.

Los autores de los ensayos, haciéndose cargo de uno o más conceptos clave de la Introducción, contribuyen a dirimir la afiliación política del pensamiento político kantiano: Kant, ¡era un pensador liberal?, ¿o un defensor del despotismo ilustrado?, ¿fue republicano?

El descubrimiento de la ley moral y de la buena voluntad como lo único irrestrictamente bueno en el universo hace difícil construir un sistema político y jurídico, dado que ni siquiera el sujeto de la voluntad puede estar seguro de actuar en consonancia con ella.

\section{La Fundamentación de la metafísica} de las costumbres hace abstracción de las peculiaridades de la naturaleza humana, no considera qué principios ni qué argumentos deben desarrollarse para aplicar la ley moral a la contingencia de la naturaleza humana. Esto hace del proyecto de una metafísica de las costumbres algo mucho más complicado de lo que hubiera pensado Kant. El problema aparece planteado en los dos ensayos de la primera parte: ambos discuten el papel de la naturaleza humana en el derecho y la moral kantianos. Para Kant, el trato moral corresponde al respeto de la dignidad de las personas o a su humanidad. Pero tal humanidad, vista en el contexto de la naturaleza humana en su conjunto, es una particularidad que de por sí plantea un problema de aplicación al imperativo categórico.

Ernesto Garzón Valdés, en el capítulo "Siete pecados capitales kantianos", analiza siete cuestiones que Kant calificaría de graves violaciones a las normas de la ética y el derecho, y un 
atentado contra el orden democrático nacional e internacional; ${ }^{1}$ las cuales están determinadas por esta particularidad ineludible de la condición natural del hombre: I) la creencia de la naturaleza angélica del hombre (su presunta bondad natural). Kant sabía que el ciudadano es un ser de carne y hueso, con debilidades y virtudes, por ello propició un sistema político que pudiera regir en una sociedad de egoístas: una organización republicana o liberal, como diríamos actualmente. ${ }^{2}$ II) El condicionamiento de la voluntad por concepciones de la felicidad. Éste constituía, según Kant, la violación misma del principio de autonomía; destruye el núcleo mismo de la moralidad individual: la autonomía. ${ }^{3}$ III) La violación del principio de publicidad de las leyes. Según Kant, sería un pecado conceptual: son injustas to- das las acciones que refieren al derecho de otros hombres cuyos principios no soportan ser publicados. ${ }^{4}$ IV) La intervención en los asuntos internos de los Estados, equivalente a la violación del principio de no intervención en los asuntos internos de los Estados. En la Paz perpetua Kant argumenta: "Ningún Estado debe inmiscuirse por la fuerza en la constitución y gobierno de otro". ${ }^{5}$ V) El colonialismo. Para Kant era una de las manifestaciones más crueles de las relaciones internacionales, volvía imposible un comercio moralmente aceptable. ${ }^{6}$ VI) La imposición de una autoridad mundial suprema que sería un poder de legibus solutus, constituía una grave violación al ius Gentium. ${ }^{7}$ VII) La guerra. Toda la filosofía práctica de Kant es una propuesta de paz entre las personas y las naciones. Su proposición al respecto

Ernesto Garzón Valdés, "Siete pecados capitales kantianos", en Forzados a ser libres. Kant y la teoría republicana del derecho, Juan Ormeño Karzulovic y Miguel Vatter, eds. (Santiago de Chile: FCE, 2017), 25.

Garzón Valdés, "Siete pecados capitales”, 29.

Garzón Valdés, "Siete pecados capitales”, 30-31.

Garzón Valdés, "Siete pecados capitales", 32.

Garzón Valdés, "Siete pecados capitales", 33-34.

Garzón Valdés, "Siete pecados capitales”, 37.

Garzón Valdés, "Siete pecados capitales”, 39. 
fue la vigencia de un derecho cosmopolita y la consolidación de regímenes republicanos.

El ensayo de Juan Manuel Garrido: "¿Y si la vida no fuera un derecho? Ser vivo e ius necessitatis" asume el problema de la antropología kantiana y sus efectos en su concepción del derecho, en particular, las razones que llevaron a Kant a negar un ius necessitatis; a excluirlo del orden jurídico. ${ }^{8}$ En la tradición jurídica occidental (Cicerón, Tomás de Aquino, Pufendorf, Rousseau) ha existido desde siempre una reflexión en torno al derecho de necesidad (ius necessitatis); incluso existe la figura del robo famélico. Se trata de un derecho a exceptuarse de la regulación penal externa o positiva, para asegurar la propia vida y la integridad del cuerpo. Este derecho es esencial para la constitución de la soberanía, definida como la autorización para decidir la excepción, la situación de necesidad o emergencia.
Este derecho de necesidad supone que la vida de cada uno es objeto de propiedad y derecho. Esta tradición considera que el ser vivo tiene el derecho natural de preservarse. Según Garrido, la revolución crítica de Kant, en particular la fundación de la moralidad en la ley de la razón, rompe con esta idea. En sí misma y por sí misma la vida no tiene — piensa Kant— derechos; sólo puede ser sujeto de derechos y de propiedad el ente racional finito considerado como agente autodeterminado de la acción, es decir, la persona humana (voluntad libre). ${ }^{9}$ En sí mismo, por sí mismo, el ser vivo queda fuera del orden del derecho. Este capítulo analiza en qué posición nos deja esta transformación cuando se trata de entender el estado de necesidad.

El tema de los ensayos de la segunda parte del libro: moral y derecho, es la distancia que separa la teoría moral kantiana de su pensamiento jurídico, es decir, la moral y el derecho están

8 Juan Manuel Garrido, “¿Y si la vida no fuera un derecho? Ser vivo y ius necessitatis”, en Ormeńo y Vatter, editores, Forzados a ser libres, 51 y 54 .

9 Garrido, “¿Y si la vida no fuera un derecho?”, 47. 
alejados en el actuar del hombre. Tradicionalmente, se ha supuesto que la teoría kantiana del derecho y del Estado se funda en su teoría moral; sin embargo, la relación entre ambos campos es particularmente problemática.

El ensayo de Christoph Horn, “¿Qué es erróneo en una interpretación moral de la filosofía política de Kant?", argumenta contra la continuidad estructural entre la filosofía moral de Kant y la política y jurídica, que la literatura especializada da por supuesta; es el caso de Otfried Höffe, Karlfried Herb y Bernd Ludwig ${ }^{10}$ quienes expresan la ampliamente extendida apreciación, según la cual, tanto la Doctrina del derecho como la Doctrina de la virtud tienen su origen en el imperativo categórico. Horn argumenta en contra, tratando de mostrar, primero, la falta de apoyo de semejante tesis en los textos de Kant y, además, para funcionar, tendría que suponer una interpretación de la teoría moral kantiana incompatible con rasgos esenciales de la misma. Es cierto, señala Horn, que Kant trata la moral y el derecho conjuntamente en la "Introducción" a La metafísica de las costumbres; en definitiva, ambos fenómenos caen en el campo temático de una doctrina normativa de las costumbres. En realidad, hace esto no para derivar el derecho de la moral, sino para delimitarlos mutuamente. ${ }^{11}$ Por otra parte, la posición kantiana que busca legitimar la estatalidad tiene enormes dificultades por sí misma, oscila entre diversas variantes del estructuralismo (entre Hobbes y Locke) ${ }^{12}$ y recurre a una compleja teoría de la propiedad: quienes sostienen la interpretación moral, dice Horn, deberían poder responder por qué la Doctrina del derecho aísla, en estricto sentido, la cuestión de la propiedad del resto de los derechos individuales subjetivos. Si Kant quisiera afirmar la necesidad moral de un orden jurídico

10 Christoph Horn, “¿Qué es erróneo de una interpretación moral de la filosofía política de Kant? ”, en Forzados a ser libres, 69.

11 Horn, “¿Qué es erróneo de una interpretación”, 70.

12 Horn, “¿Qué es erróneo de una interpretación”, 71, 81. 
estatal, ¿por qué no defiende un individualismo normativo completo? Kant intenta legitimar la propiedad, la caracteriza como un instrumento irrenunciable de la libertad. ${ }^{13}$

Como apunta el autor, Kant no es un moralista político; entonces, ¿cómo se relacionan el postulado jurídico de la razón práctica con la moral? En el primer caso, se trata de una exigencia teórica-práctica de la razón, pero no un mandamiento categórico-normativo de la misma. Su conclusión es que la concepción que Kant tiene de lo político es, ciertamente, de corte normativo, pero no es genuinamente moral. ${ }^{14}$

De manera semejante, Marcus Willaschek, en su ensayo "Derecho y coacción. ¿Puede derivarse la concepción del derecho de Kant de su teoría moral?", sostiene que dada la conexión analítica que, según Kant, existe entre derecho y coacción, hay que rechazar cualquier intento de derivar la concepción kantiana del derecho del imperativo categórico. ${ }^{15}$ Willaschek defiende, además, que tal concepción del derecho tiene un componente social o intersubjetivo, del cual carece el imperativo categórico, en apariencia. Según el autor, el argumento que imposibilita tal derivación es que una característica particular de la concepción kantiana del derecho requiere de una especie de integración social, que no se necesita para la moral en cuanto tal. Esta característica explica la relación analítica entre el derecho y la coacción y, por consiguiente, hace imposible derivar la concepción del derecho de Kant de su teoría moral. ${ }^{16}$ Más adelante, el autor insiste en que la concepción del derecho es intrínsecamente social, en un sentido en que la teoría moral no lo es. La estructura social de la esfera jurídica, junto con la imposibilidad del conflicto entre derechos, requiere que la coacción sea jurídicamente legítima,

\footnotetext{
13 Horn, “¿Qué es erróneo de una interpretación”, 84-85.

14 Horn, “¿Qué es erróneo de una interpretación”, 93-96.

15 Marcus Willaschek, "Derecho y coacción. ¿Puede derivarse la concepción del derecho de Kant de su teoría moral?”, en Forzados a ser libres, 97.

16 Willaschek, “Derecho y coacción”, 114-115.
} 
incluso cuando no lo sea desde el punto de vista puramente moral. ${ }^{17}$

Nicolás Vargas Carlier escribe "A propósito de finalidad y formalidad en la formulación del imperativo categórico kantiano", donde recorre el camino inverso al de los anteriores ensayos: trata de conectar La metafisica de las costumbres y la Doctrina del derecho contenida en ella, con la noción de imperativo categórico. Según él, la moral kantiana contiene en sus fundamentos una metafísica particular, latente en su estructura, que es igualmente importante, para la concreción de la teoría en los campos particulares del derecho y la ética. La convicción más profunda de este capítulo es que la fórmula kantiana del imperativo categórico contiene más que una mera forma a la cual adecuar nuestra praxis. ${ }^{18}$ El imperativo categórico contiene, desde siempre, la exigencia de un saber indeterminado, no conceptual, un saber sin finalidad que compro- mete al deseo más íntimo de nuestra voluntad, determina toda praxis moral y subyace, en último término, a todo juicio práctico. El autor intenta mostrar la influencia de la Crítica del juicio en el proyecto de La metafísica de las costumbres y, por lo mismo, en la Doctrina del derecho. ${ }^{19}$

La tercera parte: La libertad del derecho, se centra en la discusión sobre la libertad articulada por el concepto de derecho de Kant. Si el derecho significa nada más y nada menos que la recíproca autorización para coaccionar nuestras elecciones, de tal manera que deje para todos un espacio de acción libre de interferencia, entonces cabe la pregunta: ¿qué tipo de libertad es ésta, que no sólo es compatible con la mutua coacción, sino que además es posibilitada por ella? Todo parece indicar que se trata de una concepción mínima de la libertad jurídica, basada en el principio de no impedimento. ${ }^{20}$

\footnotetext{
17 Willaschek, “Derecho y coacción”, 125.

18 Nicolás Vargas Calier, "A propósito de finalidad y formalidad en la formulación del imperativo categórico kantiano", en Forzados a ser libres, 132.

19 Vargas Calier, "A propósito de finalidad y formalidad”, 141.

20 Autor, "Texto", en Forzados a ser libres, 146.
} 
Esta parte comienza con el ensayo de Eduardo Molina Cantó "Libertad y exterioridad", el cual analiza la relación entre la libertad interior, que caracteriza la posibilidad de un actuar moral, porque se basa en el concepto de una voluntad que no puede ser coaccionada; y la libertad exterior, que define las acciones conforme a derecho y sí puede coaccionarse.

Kant destaca que el derecho es obligatorio o vinculante sólo en la medida en que concierne a las relaciones prácticas meramente exteriores de una persona con otra, esto es, sus acciones consideradas como hechos. ${ }^{21}$ Así, el principio universal del derecho, según Kant, sólo regula las máximas de los agentes en la medida en que éstas se realizan y expresan exteriormente mediante acciones. Hacer de este principio una máxima de nuestras acciones, es decir, determinarnos nosotros mismos por esa ley universal, agrega Kant, es otro asunto circunscrito al ámbito estrictamente moral de la autodeterminación interna de la voluntad, por tanto, no viene al caso considerarlo desde un punto de vista jurídico. El autor intenta mostrar cómo se articula la libertad exterior con la interior en la filosofía kantiana del derecho, a la luz de la distinción entre libre arbitrio y voluntad, y de las distintas nociones de libertad que se logran distinguir en la filosofía crítica en su conjunto. ${ }^{22}$

Los siguientes dos ensayos, los capítulos viI y viII, se centran en el deber jurídico de respetar la libertad exterior de las personas. Esta noción aparece en la Introducción a la Doctrina del derecho, antes de la distinción entre derecho natural o privado y derecho civil o público, es decir, antes de la teoría de la propiedad y del Estado que forman las dos partes de la Doctrina del derecho. El ensayo de Juan Ormeño Karzulovic, "Violencia y autorrespeto: las bases kantianas de la libertad exterior", pretende aclarar cuál

21 Eduardo Molina Cantó, "Libertad y exterioridad”, en Forzados a ser libres, 154-155.

22 Molina Cantó, "Libertad y exterioridad”, 156. 
es el papel sistemático que desempeña la doctrina de los deberes jurídicos en la Doctrina del derecho. A diferencia de otras interpretaciones, Ormeño trata de vincular estos deberes -atribuidos tradicional, aunque falsamente, al jurista romano Ulpiano- con la argumentación contractualista en general, arguyendo que, para llevar una vida honesta en el sentido jurídico relevante, es necesario entrar con otros en una condición civil: si al agente no le es posible evitar dañar a otros, entonces — señala el autor- éste debe entrar con otros en una sociedad, en la que a cada cual se le pueda mantener lo suyo. ${ }^{23}$ Ormeńo examina el vínculo entre el primer deber (vive honestamente) y el derecho innato a la libertad. Señala Kant que el primer deber se explicará como obligación surgida del derecho de la humanidad en nuestra propia persona. Si con ello se alude al derecho innato a la libertad, en cuanto independencia del arbitrio coactivo de algún otro, entonces el primer deber parece ser propiamente jurídico (exterior) y no de carácter moral. ${ }^{24}$ Aunque pueda mostrarse que este derecho innato a la libertad es representado por Kant como condición de posibilidad de la agencia jurídica en general, la existencia de un estado civil (una situación de derecho público) es, en realidad, la condición sin la cual tal derecho innato no podría ser ni realizado ni expandido en una esfera de acción individual libre de interferencia arbitraria. Precisamente —dice Ormeño-, el ingreso en un estado jurídico garantiza una esfera de libertad exterior, esto es, un ámbito que, de existir, provee al agente de las condiciones bajo las cuales puede seguir gozando de su derecho interno o, si se prefiere, de la posesión de sí mismo. ${ }^{25}$

Miguel Vatter, en su capítulo "El derecho a tener derechos y las reglas de Ulpiano en la Doctrina del derecho kantiana" también fija su atención en

23 Juan Ormeńo Karzulovic, "Violencia y autorrespeto: las bases kantianas de la libertad exterior”, en Forzados a ser libres, 164.

24 Ormeño Karzulovic, "Violencia y autorrespeto", 166.

25 Ormeño Karzulovic, "Violencia y autorrespeto", 173 
la interpretación de los deberes jurídicos, a la luz del único derecho innato que reconoce Kant: el derecho a la libertad exterior. Éste no es sino nuestro derecho innato a la no-dominación, es decir, el derecho de cada ser humano de gozar del estatus de ser sui iuris. Sin embargo — dice el autorhay una tensión en el pensamiento de Kant entre el deber de obedecer al soberano fáctico y el derecho innato a la libertad exterior; la cual se puede resolver sólo si a Kant se le interpreta como un pensador republicano. ${ }^{26} \mathrm{Si}$ se acepta que el derecho innato a la libertad exterior no es sino gozar del status de ser sui iuris, homo liber, la Doctrina de derecho en Kant es, desde un comienzo, republicana. ${ }^{27}$ Para Kant - comenta el autor - mi derecho a la libertad exterior no puede depender de una libertad externa: esto significa que mi derecho a tener derechos no depende de la ley natural, menos de la ley civil. La persona jurídica no puede transformarse en objeto de nadie. ${ }^{28} \mathrm{El}$ derecho a tener derechos es el derecho a ser ciudadano. Pero ser ciudadano no es lo mismo que ser el autor de las leyes positivas. Kant atribuye al pueblo una función colegislativa sólo con respecto a la idea de una constitución. Esta última protege la libertad de no ser gobernado sin mi consentimiento, pues si alguien decretara algo respecto de otro, siempre es posible que cometa una injusticia contra él, pero nunca en aquello que decide sobre él. ${ }^{29}$

La cuarta parte: Moral, historia y cosmopolitismo consta de dos capítulos, en los cuales se busca la relación entre derecho natural o privado y derecho civil o público; o lo que es lo mismo, entre la propiedad y el Estado. Los autores de estos dos capítulos: Alessandro Pinzani y Daniel Loewe tienen en común la propuesta de que el horizonte último de la teoría política y jurídica kantiana es el horizonte cosmopolita de La paz perpetua.

26 Miguel Vatter, "El derecho a tener derechos y las reglas de Ulpiano en la Doctrina del derecho Kantiana”, en Forzados a ser libres, 177.

27 Vatter, "El derecho a tener derechos", 182.

28 Vatter, "El derecho a tener derechos", 185.

29 Vatter, "El derecho a tener derechos", 190-191. 
Pinzani escribe "Justificación normativa y justificación funcional de la necesidad del Estado de Kant", donde insiste (como el título indica) en la justificación de la necesidad de salir del estado de naturaleza para entrar en el estado civil. Analiza las diversas interpretaciones que colocan a Kant próximo a Hobbes o Locke, defendiendo la idea de que el Estado surge porque el hombre tiene el deber de erigirlo. Esta obligación constituye el primer e incondicional deber para los seres humanos. La justificación ofrecida por Kant es que la creación de una sociedad civil representaría condición formal (conditio sine qua non) de todos los restantes deberes externos. ${ }^{30}$ Pinzani trata de mostrar cómo la necesidad de salir del estado de naturaleza para entrar en el civil, Kant la funda a partir de una perspectiva normativa, pero no moral en sentido estricto, sino en sentido lato: como uno más amplio que incluye la esfera del derecho y la de la ética o moral, utilizado en $L a$ metafísica de las costumbres. ${ }^{31}$

Daniel Loewe, en "Libertad y propiedad en la fundamentación del Estado y el cosmopolitismo kantiano", vuelve sobre el estado de naturaleza; argumenta que abandonar éste y entrar en un estado ciudadano no es una cuestión relativa al querer sino al deber, es decir, a un dictado de la razón práctica: una pretensión radical de Kant. ${ }^{32}$ Según el filósofo alemán, la constitución del Estado es necesaria porque es condición de posibilidad de otra cosa absolutamente necesaria, de un fin en sí. Para él la propiedad y la libertad son necesarias en sí; pues constituyen el fundamento de su filosofía política. ${ }^{33}$

Más adelante, Loewe considera la relación entre estado civil y su destino cosmopolita, sostiene que hay una tensión entre esta pretensión de

$30 \quad$ Alessandro Pinzani, "Justificación normativa y justificación funcional de la necesidad del Estado de Kant", en Forzados a ser libres, 201-202.

31 Pinzani, “Justificación normativa”, 197.

32 Daniel Loewe, "Libertad y propiedad en la fundamentación del Estado y el cosmopolitismo kantiano", en Forzados a ser libres, 209.

33 Loewe, "Libertad y propiedad en la fundamentación", 210-211. 
la necesidad del Estado y los artícu- conformar una República Mundial de los definitivos de La Paz perpetua: a) Estados o una República Mundial el derecho del Estado, que regula las relaciones entre los ciudadanos de un Estado, y entre éstos y el Estado correspondiente; b) el derecho de gentes, que regula las relaciones entre los Estados y c) el derecho cosmopolita, que regula la relación entre personas naturales y Estados extranjeros. Éste es un suplemento necesario, porque cubre las relaciones que no son abarcadas ni por el derecho del Estado ni por el de gentes.

Según Kant —dice el autor- la realización de estos tres derechos, que cubren todas las relaciones de derecho público posibles, garantizaría la paz perpetua y no sólo momentos de paz bajo la amenaza permanente de conflictos armados. ${ }^{34}$ Por otra parte, los Estados con relaciones recíprocas requieren, según Loewe, sobrepasar la confederación de Estados propuesta por Kant y de Ciudadanos del Mundo. ${ }^{35}$

Esta obra es recomendable para filósofos, juristas y políticos, Immanuel Kant es un autor que está en el tiempo, es decir, su pensamiento no pierde vigencia ni puede ser relegado. Es necesario regresar de manera frecuente a él, con un buen espíritu crítico, sabiendo que siempre se encontrará una luz para el problema a tratar. 